\title{
Mechanical Properties of Samurai Swords (Carbon Steel) Made using a Traditional Steelmaking Technology (tatara)
}

\section{Okayasu M*, Sakai H and Tanaka T}

Department of Materials Science and Engineering, Ehime University 3 Bunkyo cho, Matsuyama, Ehime, 790-8577, Japan

\begin{abstract}
The material and mechanical properties of samurai swords (Japanese swords), made using a traditional steelmaking technology (tatara), are investigated experimentally. The quality of these swords appears to be low because of the presence of a large number of inclusions, including oxide- and phosphorus-based structures; however, their mechanical properties are relatively good because of their fine-grained structure and high residual stress. The swords consist of several carbon steels, with a fine microstructural formation being obtained in the sharp edge of the sword (knife) as a result of the forging process. There is high residual compressive stress in the thick edge of the sword (mandrel), caused by bending due to the martensitic phase transition in the sharp edge. The carbon content of the sword varies depending on region: the sharp edge is found to have $0.55 \% \mathrm{C}$, which is more than twice the amount in the thick edge. The Vickers hardness and tensile strength in the sharp edge region are about 6 and $1 \mathrm{GPa}$, respectively, which are about three times higher than the corresponding values in the other regions of the sword. The hardness in the sharp edge region is almost the same as in a conventional carbon steel $\left(\mathrm{Fe}-\mathrm{C}_{0.5}\right)$ produced by presentday steelmaking technology. The tensile strength of the sharp edge of the sword is relatively high, but is slightly lower than that of the conventional $\mathrm{Fe}-\mathrm{C}_{0.55}$ steel, despite the fine-grained structure and high residual compressive stress in the sharp edge region. This is caused by the presence of various inclusions in the sword.
\end{abstract}

Keywords: Sword; Steel; Tamahagane; Mechanical property; Microstructural characteristic

\section{Introduction}

The samurai were a class of warriors in ancient Japan, originating more than 1000 years ago and having a relatively high social position. Samurai always carried Japanese-style swords, generally on the waist, as part of their role as protectors of society. They were often required to use these swords in battle, and there were a number of battles in ancient Japan in which many casualties were caused by these swords. Old swords have been found throughout Japan, and their history and that of the society in which they were made have been investigated by historians and archaeologists. The traditional technology for making samurai swords was established a long time ago and then handed down through the centuries. Even today, there are still craftsmen making samurai swords in Japan, even though these are no longer intended for actual use. Because of their beautiful designs, these swords have acquired the status of aesthetic objects in Japanese society [1].

Samurai swords are made using a traditional steelmaking technology, tatara, developed in ancient Japan. Steels made by tatara are called tamahagane. Tamahagane is made by the following process (Figure1) [2]. A specific iron sand and charcoal are fused together in a clay pot to make carbon steel (Figure 1a). The material is then drawn out into a thin plate. This plate is cut into smaller plates, which are then separated according to their carbon content and thus hardness (Figure $1 \mathrm{~b}$ ). Each plate is folded and forged repeatedly to produce a fine-grained structure. The sword is constructed by combining steel plates with different carbon contents in layers, with high-carbon steel being used to form the sharp cutting edge (the knife) and lowcarbon steels for the side planes and thick edge (the mandrel). The combined steel plates are repeatedly folded and stretched during hightemperature forging to produce the final shape of the sword. After the edge has been ground and the sword has been heated to $770^{\circ} \mathrm{C}$, sandy loam soil is coated on the side planes (but not on the sharp edge) before it is quenched in water. The partial coating allows the hardness of the sword to be controlled during quenching, with high and low hardnesses being obtained in the knife and mandrel, respectively. The high hardness of the sharp edge of the sword is due not only to its high carbon content but also to martensite formed during the severe quenching of the uncoated steel. In addition, the volume expansion due to the martensitic transformation, which occurs only in the sharp edge, produces the desired bending of the sword. After quenching, the sword is finished by grinding and polishing to produce a sharp edge as well as a beautiful design [3].

Recent investigations of the material properties of Japanese swords have shown that the steel contains a large number of inclusions [2]. Because of martensite formation, the Vickers hardness of the sharp edge area is as high as HV 866, compared with a value of 787 for the thick edge area [4].

Although samurai swords have been employed for various uses over a very long period, there is an apparent lack of information regarding their mechanical and material properties. In particular, there has been no detailed description of the effects of the material characteristics of the steel, such as grain size, internal strain and inclusions, on the mechanical properties of these swords. In fact, a Scopus search reveals that only 12 searchable "Japanese sword and material property" academic papers have been published. This might be due to the technical difficulties of obtaining suitable test specimens from the thin swords. Moreover, it is difficult to obtain real swords made by the traditional tatara steelmaking technology. The aim of the present work is therefore

${ }^{*}$ Corresponding author: Okayasu M, Department of Materials Science and Engineering, Ehime University 3 Bunkyo cho, Matsuyama, Ehime, 790-8577, Japan, Tel/Fax: +81 89927 9811; E-mail: mitsuhiro.okayasu@utoronto.ca

Received March 16, 2015; Accepted April 04, 2015; Published April 10, 2015

Citation: Okayasu M, Sakai H, Tanaka T (2015) Mechanical Properties of Samurai Swords (Carbon Steel) Made using a Traditional Steelmaking Technology (tatara). J Material Sci Eng 4: 162. doi:10.4172/2169-0022.1000162

Copyright: @ 2015 Okayasu M, et al. This is an open-access article distributed under the terms of the Creative Commons Attribution License, which permits unrestricted use, distribution, and reproduction in any medium, provided the original author and source are credited. 
Citation: Okayasu M, Sakai H, Tanaka T (2015) Mechanical Properties of Samurai Swords (Carbon Steel) Made using a Traditional Steelmaking Technology (tatara). J Material Sci Eng 4: 162. doi:10.4172/2169-0022.1000162

(a)

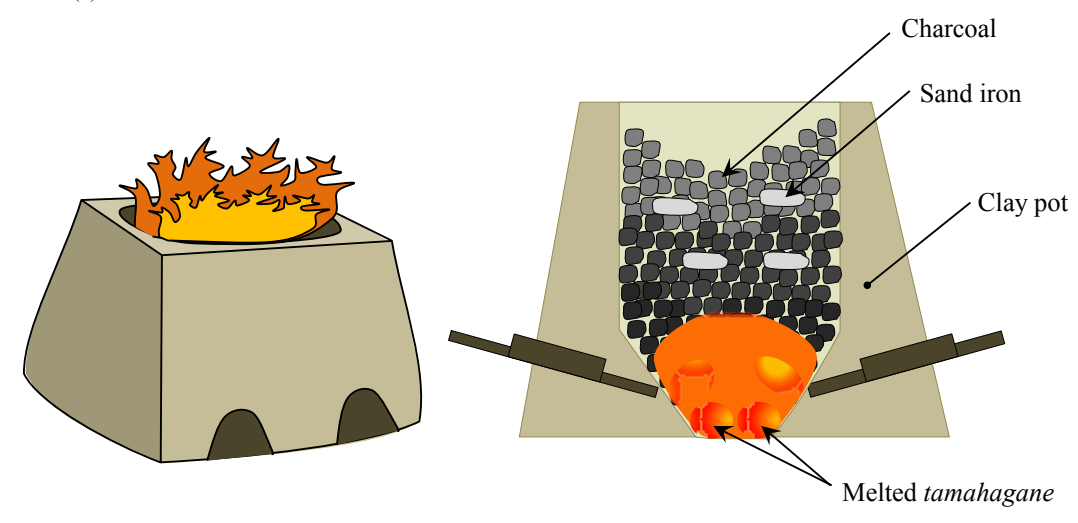

(b)
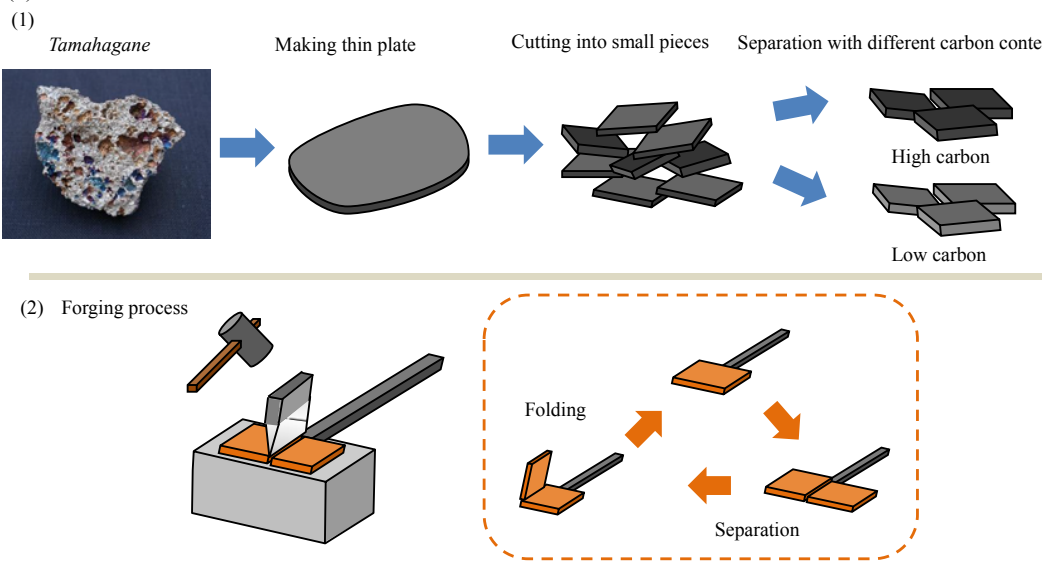

(3)

Forging at high temperature $(900 \sim 700 \rrbracket)$
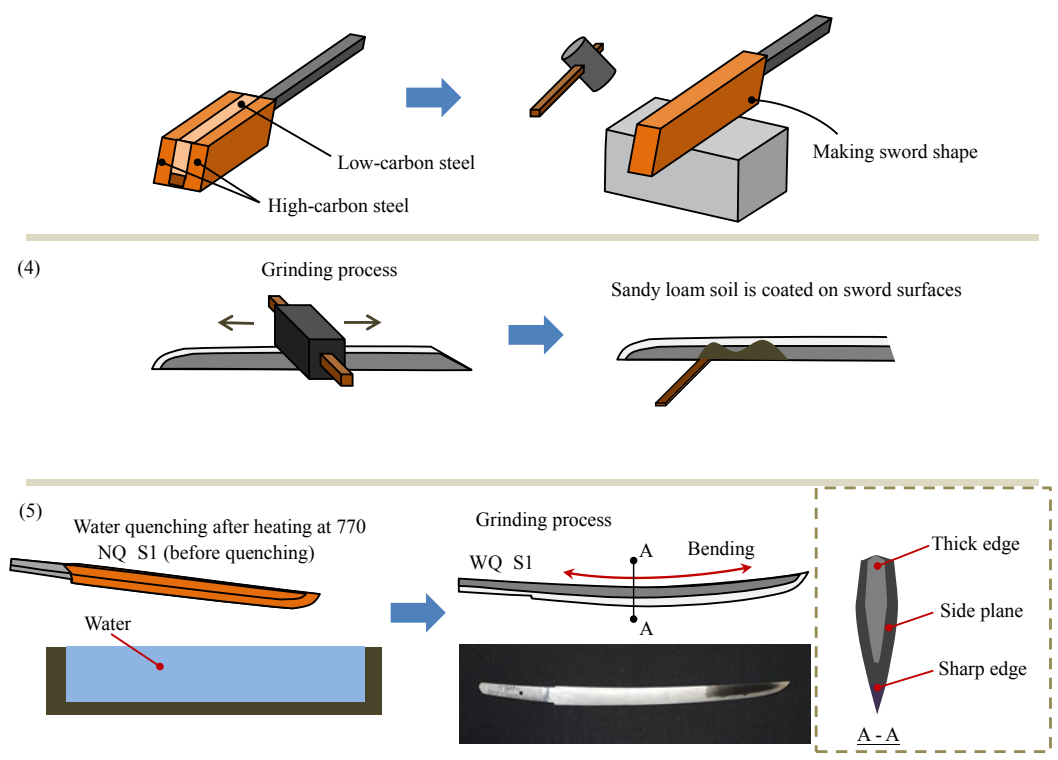

Figure 1: Schematic illustrations of the tatara steelmaking technology for the production of samurai swords. The tamahagane and sword shown here were provided by the research center of ancient East Asian iron culture in Ehime University. 
to examine systematically the material and mechanical properties of an actual samurai sword using tiny specimens.

\section{Experimental Procedures}

For the present investigation, tamahagane was created using iron sand from Shimane Prefecture, in the west of Japan. Based upon the tatara steelmaking method shown in Figure 1, samurai swords were created by an experienced Japanese swordsmith. Two types of sword were prepared, with (WQ-S) and without (NQ-S) quenching. The WQ-S sword was slightly bent after quenching, although there was no clear bend in the unquenched sword (Figures $1 \mathrm{~b}$ and $\mathrm{b} 5$ ). Test specimens were taken from each sword as shown in Figure 2. The specimens were dumbbell-shaped plates of dimensions $3{ }^{\star} 2.5^{\star} 1.5 \mathrm{~mm}$. In addition, specimens were taken from conventional high-carbon steel $\left(\mathrm{Fe}-\mathrm{C}_{0.55}: \mathrm{S} 55 \mathrm{C}\right)$ for comparison of mechanical properties. Tensile tests were conducted at a loading speed of $1 \mathrm{~mm} / \mathrm{min}$ until complete fracture of the specimen. Tensile properties were examined at room temperature using an electro-servo-hydraulic system with $50 \mathrm{kN}$ capacity.

Failure characteristics of the sword were examined by the cyclic loading following method: the samples of the sharp edge and $\mathrm{S} 55 \mathrm{C}$ were cyclically loaded $(1 \mathrm{kN})$ to hit on the surface of the hard ceramic at $1 \mathrm{~Hz}$, e.g., silicon nitride $\left(\mathrm{Si}_{3} \mathrm{~N}_{4}\right)$ (Figure 3 ), and the damage speed was investigated directly.

The microstructural characteristics of the swords and the S55C steel were examined by optical microscopy and energy-dispersive $\mathrm{X}$-ray spectroscopy (EDX). Residual stress was investigated by X-ray diffractometry (XRD), using $\mathrm{Cu} \mathrm{Ka}$ incident radiation (X'Pert Pro, PANalytical), with a measurement time of $20 \mathrm{~min}$.

(a) Location of specimen collection

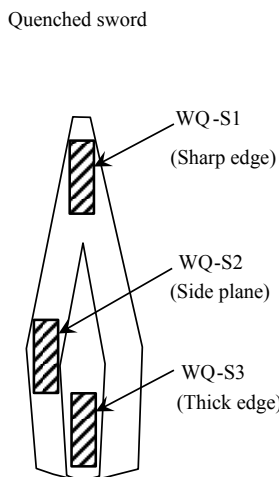

Unquenched sword

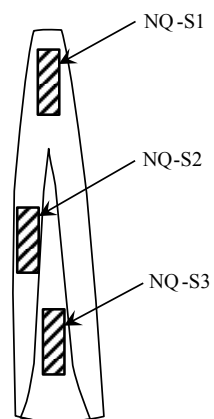

(b) Tensile test specimen

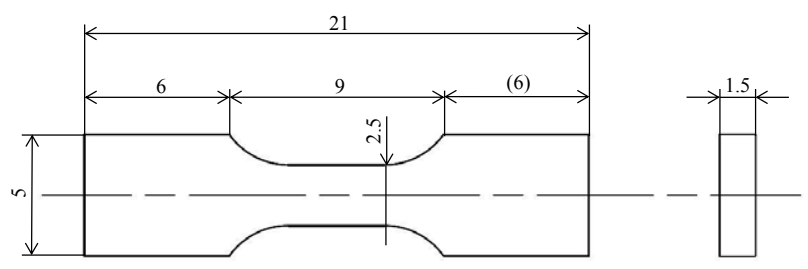

Figure 2: Schematic diagram showing the locations from which the samples were taken and the dimensions of a tensile test specimen.

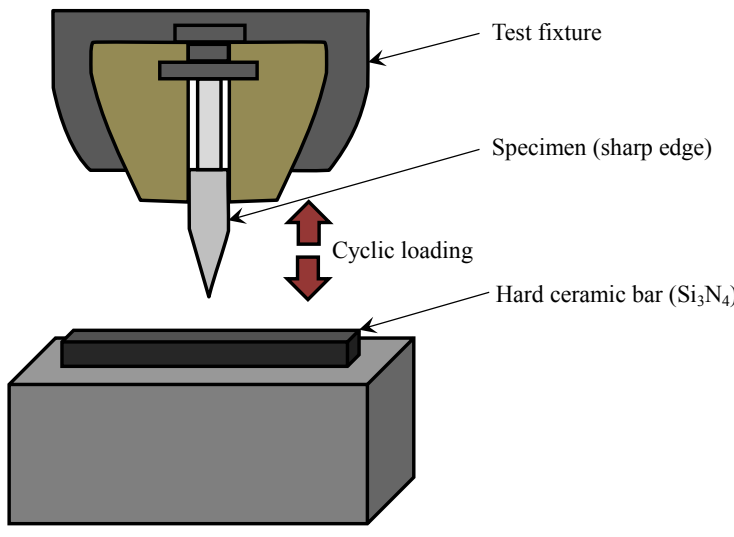

Figure 3: Experimental setup for examination of the failure characteristics during the cyclic loading.

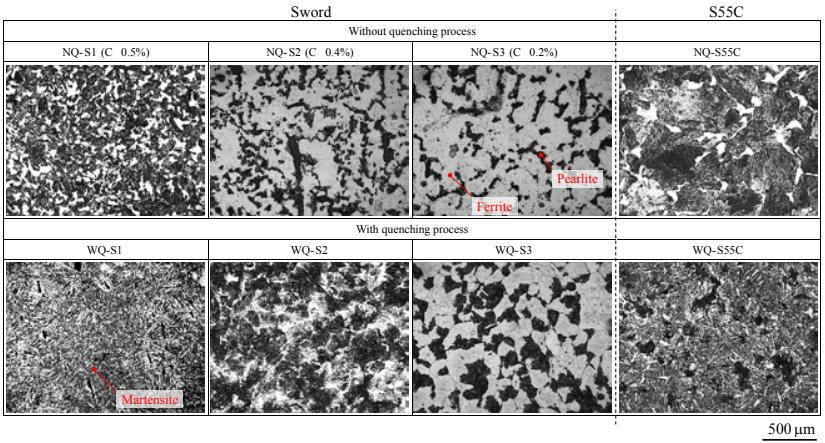

Figure 4: Optical micrographs of the swords and S55C with and without quenching.

\section{Results and Discussion}

\section{Microstructural characteristics}

Figure 4 displays optical micrographs of the swords and the conventional carbon steel (S55C) with and without quenching. As can be seen, the microstructures basically consist of regular ferrite and/or pearlite in both the sword and S55C samples before quenching (NQ-S and NQ-S55C). The different ratios of pearlite and ferrite indicate that the carbon content of the sword varies depending on region: $\mathrm{S} 1=0.55 \%$ C, S2 $=0.4 \%$ C and S3 $=0.2 \%$ C. The grain size also varies: for example, there are small grains in the sharp edge region of the sword and large grains in the thick edge and in the S55C. The fine-grained structure in the sharp edge region of the sword arises from the forging process. On the other hand, as a result of the quenching process, lath martensite formation can be seen (acicular structures) in the sharp edge of the sword (WQ-S1) and in the S55C sample (WQ-S55C). Because of the coating that was applied to the sword surfaces other than the sharp edge during quenching, there are no significant differences in microstructural characteristics between S2 and S3, whereas it is obvious that the heating process has led to a decrease in the amount of ferrite phase in S2 and S3 compared with S1.

The swords have a complicated microstructure, with several steel plates combined and with the formation of a martensite phase, and therefore the residual stress were examined by XRD. Representative XRD results (WQ-S1 and WQ-S3) are shown in Figure 5. It should be 

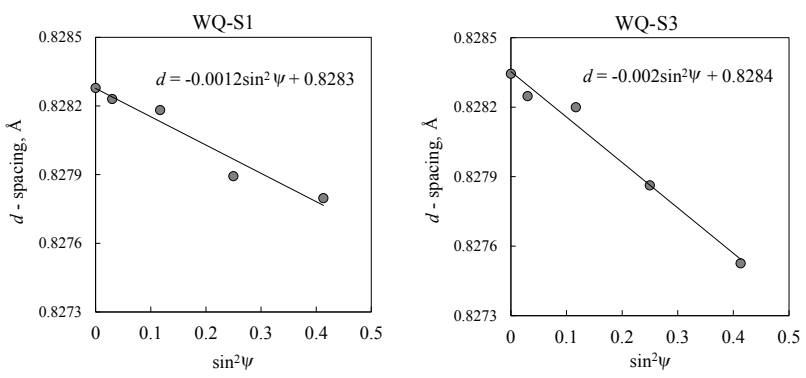

Figure 5: XRD results showing the relationship between $2 \theta$ and $\sin ^{2} \psi$ for WQ-S1 and WQ-S3.
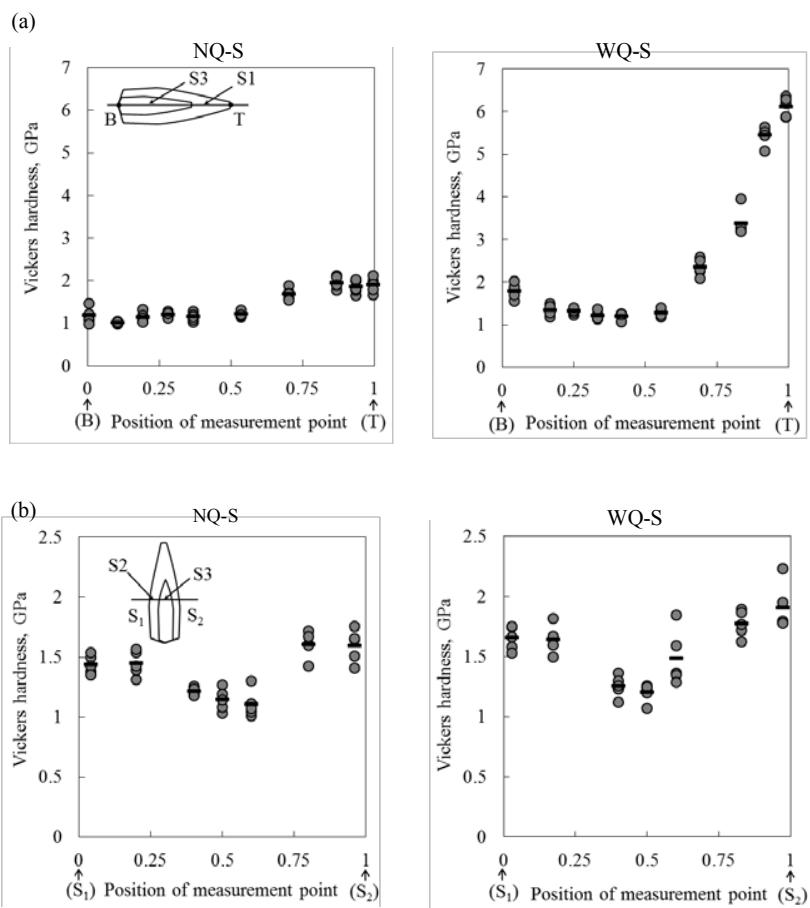

Figure 6: Variation of Vickers hardness over the cross-section of swords with and without quenching: (a) longitudinal direction; (b) lateral direction.

noted that the result for WQ-S3 shows a similar trend to that for WQS2. Different slopes of the plot of $d$-spacing versus $\sin ^{2} \psi$ are obvious, with higher slopes for WQ-S3 (and WQ-S2) than for WQ-S1. On the basis of the XRD profiles in Figure 5, the residual stress values $\sigma_{\mathrm{r}}$ can be calculated from the following equation:

$$
\square_{r}=\square \frac{E}{2(1+\square)} \cot \square \cdot \frac{\square}{180} \frac{\square(2 \square)}{\square\left(\sin ^{2} \square\right)}
$$

Where $E$ is the elastic constant and is Poisson's ratio. The residual compressive stress for WQ-S1 is found to be $133 \mathrm{MPa}$, which is approximately five times lower than that for WQ-S3 (about 750 $\mathrm{MPa}$ ). Yaso examined residual stresses in some swords by XRD and found a high residual compressive stress of $520 \mathrm{MPa}$ in the sharp edge region, which is about twice the values in the side regions [5]. This trend differs from our results. It appears that the bending of the sword during quenching releases residual stress in the sharp edge region as a result of volume expansion, while producing severe residual stress in the thick edge of the soft (weak) material because of pressure from the surrounding areas.

\section{Mechanical properties}

Figure 6 shows the variation of the Vickers hardness over the crosssection of the swords (NQ-S and WQ-S). In the longitudinal direction (Figure 6a), the hardness increases nonlinearly, with greater hardness being obtained in the sharp edge region for both sword samples. The hardness of WQ-S is greater than that of NQ-S, especially in the sharp edge region, as a result of quenching, which leads to the formation of a highly strained bcc form of ferrite with a large number of dislocations resulting in high hardness. The hardness of the top of the NQ-S sample is about $2 \mathrm{GPa}$, which is about twice that of the bottom of the NQ-S sample because of the different carbon contents of these regions. A similar difference is also seen in the lateral direction of the samples; for example, the hardness of NQ-S3 is about 30\% lower than that of NQ-S2, as shown in Figure 6b. A similar hardness profile is seen in WQ-S. Such hardness profiles are a consequence of the weakness of quenching because of the coating on these areas. Figure 7 shows the hardness results for the sword (S1) and S55C samples with and without quenching. It appears from these results that the hardnesses of the sword (NQ-S1) and S55C samples are almost the same, because of their similar carbon content. On the other hand, the hardnesses of the quenched samples (WQ-S1) are four times higher than those of the unquenched samples.

Figure 8a shows representative tensile stress-strain curves for each cast sample. It is clear that the stress-strain profiles are different depending on the sample. On the basis of the obtained stress versus strain, the tensile properties were further analyzed. Figure $8 \mathrm{~b}$ shows the results for ultimate tensile strength $\sigma_{\mathrm{UTS}}$ and fracture strain $\epsilon_{\mathrm{f}}$ for all samples. As with the results for hardness, the ultimate tensile strengths of the quenched samples (WQ-S) are overall higher than those of the unquenched samples (NQ-S), with especially high $\sigma_{\mathrm{UTS}}$ values being obtained for the sharp edge of the quenched sword (WQ-S1) as a result of martensite formation. It should be pointed out that the tensile properties of NQ-S55C are approximately 10\% higher than those of the NQ-S1 sample, even though both materials are similar carbon steels with similar hardnesses (Figure 7). To interpret this, their failure

(c) Sword vs. S55C

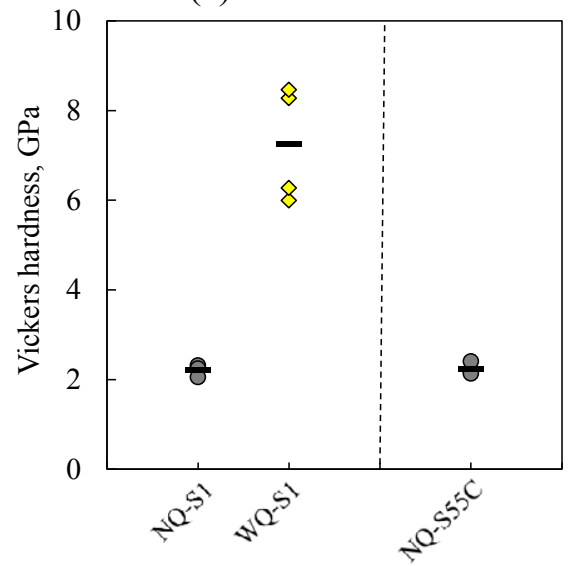

Figure 7: Vickers hardness of the sword and of S55C with and without quenching. 

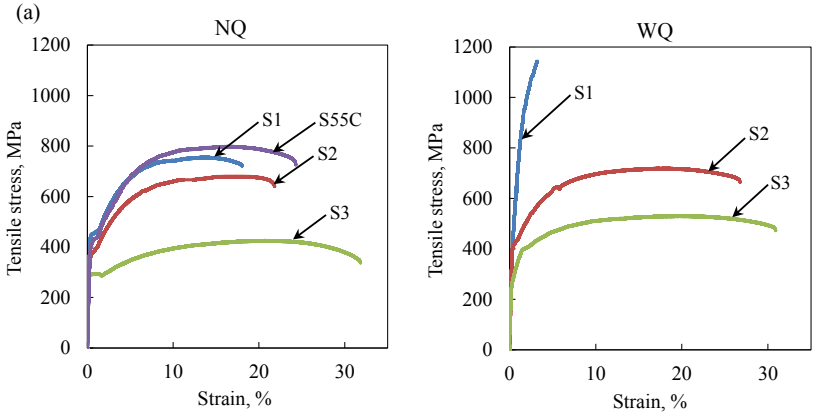

Figure 8a: Representative tensile stress versus tensile strain curves for the swords and for S55C.

(b)
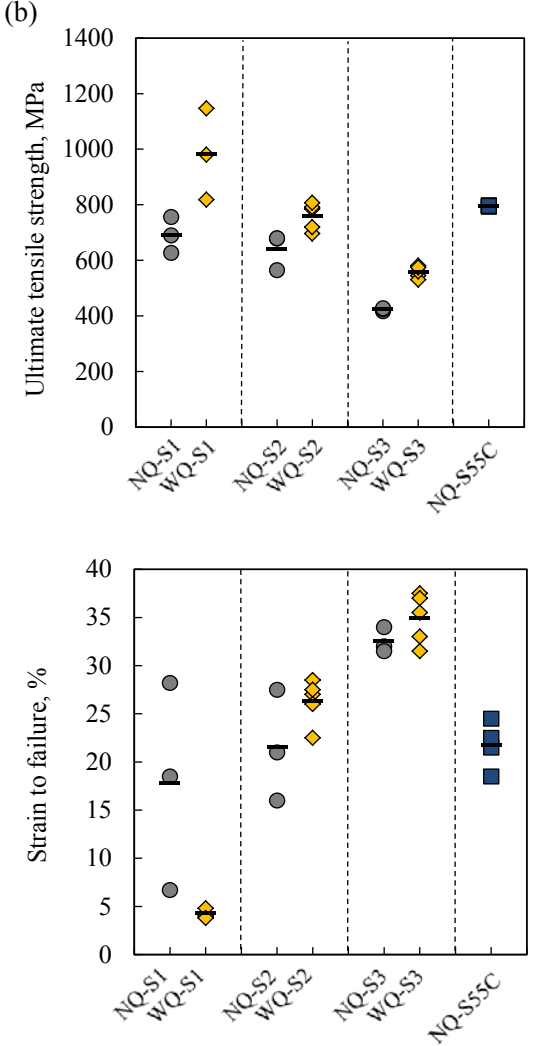

Figure 8b: Tensile properties of the swords and of S55C: ultimate tensile strength and fracture strain.

characteristics are analyzed below. Although there is a wide scatter in strain values for NQ-S1, the strain level is clearly higher than that for WQ-S1. The low strain for WQ-S1 is caused by the presence of hardened material (the martensite phase). Interestingly, despite the high tensile strengths of WQ-S2 and WQ-S3, their ductilities also seem to be high. This could be due to a reduction in residual stress caused by heating.

Damage characteristics of the sharp edge of the swords were investigated by the cyclic loading. Figure 9 depicts the variation of the failure values as a function of the cyclic number for the NQ and
WQ-S55C and WQ-S1. The failure value increases nonlinearly with increasing the cyclic number for the three samples, and especially severe damage for the NQ-S55C due to its softness. In contrast, the low failure characteristics are obtained in both WQ-S55C and WQ-S1, while the high damage resistance is detected for WQ-S55C. This could be attributed to the high mechanical properties of WQ-S55C.

\section{Fractography}

Figure 10 displays scanning electron microscope (SEM) images and EDX maps of the fracture surfaces of NQ-S1 and NQ-S55C after the tensile test. From both SEM images, it can be seen that for both samples, dimple-based ductile failure is the dominant feature, which results in the high fracture strains shown in Figure 8. However, the diameters of the dimples in the sword are clearly greater than those in the S55C sample. Such large dimples in the sword seem to be created by inclusions. From the EDX analysis, the inclusions in the middle of the dimples for NQ-S1 appear to be related to oxide- and phosphorus-based structures. Such inclusions would have been produced in the sword during the tatara steelmaking process. In contrast, no clear inclusions can be seen in the S55C samples, while small amounts of oxides and phosphorus are detected on the fracture surface. As mentioned above, the tensile strength of the NQ-S1 sample is lower than that of NQS55C, which may be due to the presence of many inclusions in the sword. From the above experimental results, it appears that the quality of tamahagane for swords may be lower because of the inclusions, but

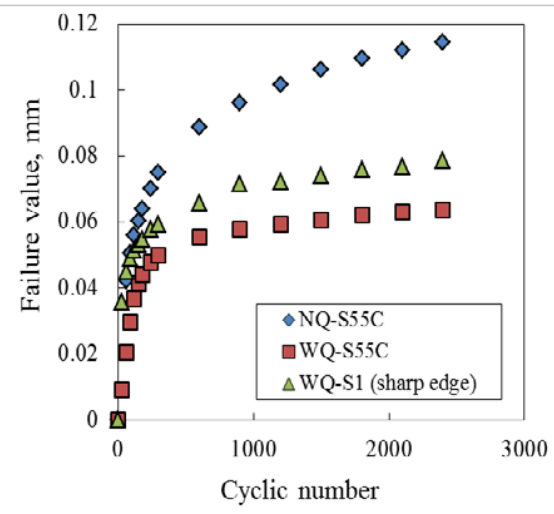

Figure 9: Variation of the damage values as a function of the cyclic number.

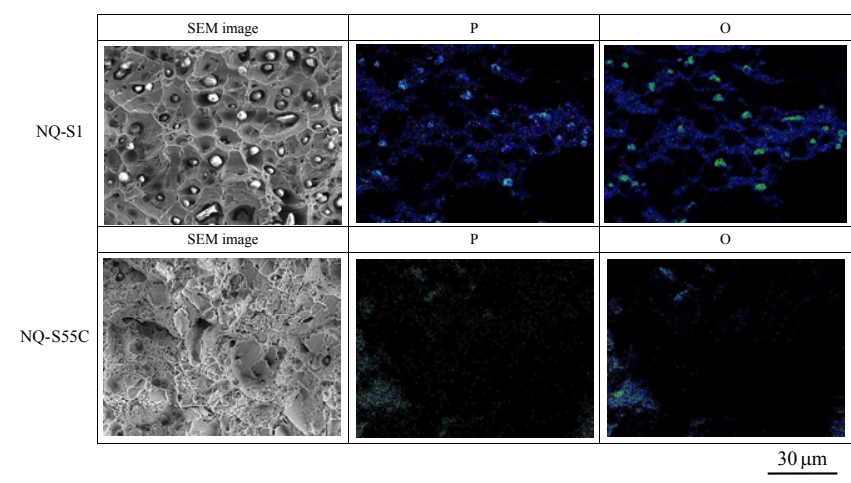

Figure 10: SEM images and EDX maps of the fracture surface for the sword and S55C samples. 
Citation: Okayasu M, Sakai H, Tanaka T (2015) Mechanical Properties of Samurai Swords (Carbon Steel) Made using a Traditional Steelmaking Technology (tatara). J Material Sci Eng 4: 162. doi:10.4172/2169-0022.1000162

Page 6 of 6

the high strength is retained because of the fine microstructure and residual compressive stress produced by the forging process.

\section{Conclusions}

The material and mechanical properties of samurai swords have been studied. On the basis of the results obtained, the following conclusions can be drawn:

1. The tamahagane from which the sword is made is formed with fine microstructures with several residual inclusions: oxide- and phosphorus-based structures. High residual compressive stress is produced in the thick edge of the sword, about three times higher than that in the other regions. The residual stress is caused by the bending of the sword arising from the volume expansion of the sharp edge due to martensitic transformation.

2. The carbon content of the sword varies depending on region, with approximately $0.55 \% \mathrm{C}, 0.40 \% \mathrm{C}$ and $0.20 \% \mathrm{C}$ in the sharp edge, side planes and thick edge, respectively. The mean maximum hardness in the sharp edge region after quenching is about $6 \mathrm{GPa}$, which is about three times higher than that in the other regions. The tensile properties of the sword are slightly lower than those of S55C in spite of the finegrained structure and high residual compressive stress in the sword. The low tensile properties of the sword are caused by the large amount of inclusions that are present.

\section{Acknowledgement}

This work was technically supported by one of the swordsmiths in Japan, Mr. T. Takaichi.

\section{References}

1. Das AK, Takami G, Ohba T, Morito S, Yaso M (2010) Traditional process produces lath martensite effectively. Appeared Mater. Australia 43: 1-5.

2. Matsumoto C, Das AK, Ohba T, Morito S, Hayashi T, et al. (2013) Characteristics of Japanese sword produced from tatara steel. J. Alloys Compd 577: S673-S677.

3. Yaso M, Takaiwa T, Minagi Y, Kubota K, Morito S, et al. (2009) Study of microstructure on cross section of Japanese sword. ESOMAT 1-5.

4. Das AK, Ohba T, Morito S, Takami G, Fujikawa T, et al. (2009) Characteristic feature found in typical tatara product, Japanese sword, ESOMAT 1-5.

5. Yaso M, Takaiwa T, Minagi Y, Kanaizumi T, Kubota K (2013) Study of Japanese sword from a viewpoint of steel strength. J. Alloys Compd 577: S690-S694. 